\title{
GEOINFORMATION SUPPORT AND WEB TECHNOLOGIES FOR PROBLEMS OF HYDROBIOLOGICAL MONITORING OF YENISEI RIVER
}

\author{
Anna Andrianova ${ }^{1,2}$, Nicolay Shaparev ${ }^{1,3}$, Oleg Yakubailik ${ }^{1, *}$ \\ ${ }^{1}$ Institute of Computational Modeling SB RAS, 660036, Krasnoyarsk, Russia \\ ${ }^{2}$ Institute of Ecology of Fishery Reservoirs, 660097, Krasnoyarsk, Russia \\ ${ }^{3}$ National Research Tomsk State University, 634050, Tomsk, Russia
}

\begin{abstract}
Results of long-term hydrobiological monitoring for the Yenisei river section from the Krasnoyarsk hydroelectric power station dam to the village Zotino (Turukhansk district of the Krasnoyarsk region) are considered. Researching of zoobenthos showed significant changes of its structure after the Krasnoyarsk HPP dam construction. In particular, the proportion of amphipods (crustaceans) in the zoobenthos biomass increased by 10 times. In the expeditionary studies, seven species of amphipods were identified, but it should be noted that only two species develop and clearly dominate among them. Data obtained during the hydrobiological research formed the basis of geospatial database developed as a result of the work. The geospatial database with the observation results is available in the ICM SB RAS geoportal. The geoportal services provide data visualization in the form of interactive thematic maps, information about the objects on the map as "tooltips", information downloading in tabular form, direct access to the data through the web mapping services. Information and analytical support for the monitoring system based on the considered approach can simplify access to the needed information, provide new opportunities for analysis and modeling, promote the development of cross-disciplinary researches.
\end{abstract}

\section{Introduction}

The Yenisei is the main water artery of Siberia, which is among the seven largest rivers of the world and the most abounding river of our country. Over many years, an extensive array of diverse biotic and abiotic data is accumulated on the Yenisei ecosystem that is a valuable material for analysis. Using of new data processing techniques such as geoinformation and cartographic modeling will provide additional information on the features of aquatic organisms spatial distribution and help to search for relationships with various environment factors.

* Corresponding author: oleg@icm.krasn.ru 
Usage of modern geoinformation system technologies and the Internet provides an effective solution of all problems related to the geospatial data submission, processing and analysis. Creation of the geospatial database with the results of field researches and implementation of geoinformation web-system for information and analytical support of the hydrobiological monitoring form the basis for interdisciplinary studies [1, 2].

\section{Hydrobiological monitoring}

It is known that fundamental change in the hydrological, hydrochemical and hydrobiological regimes happened in the Yenisei since the commissioning of the Krasnoyarsk hydroelectric power station. Consequences of the regulation can be traced at a distance of more than 1.5 thousand kilometers from the hydrounit point. Environmental transformations in aquatic communities require in-depth study and long-term monitoring both to assess the environmental damage and to develop scientific bases of strategy to overcome the negative effects and restore the biological potential of the Yenisei ecosystem. Currently, hydrobiological monitoring system is almost absent in the Yenisei.

Integrated monitoring of aquatic ecosystems is impossible without researches of such an important biological unit as the zoobenthos community. Zoobenthos consists of invertebrates (such as leeches, mollusks, crustaceans, worms, insect larvae, etc.), which live in the water bodies on the bottom surface and inside it. The role of zoobenthos in aquatic ecosystems is hard to overestimate. First, the community of benthic invertebrates is a link in the trophic chain and a food object for most Siberian fish species (sturgeon, whitefish, grayling, carp, etc.). Second, zoobenthos organisms contribute to the natural selfpurification of natural waters as they become active mineralizers of organic substances and water biofilters in their life. Third, they are reliable biological indicators for the ecological state of different water bodies as there is a clear link between the zoobenthos indices and the content of pollutants in the bottom layers of water and sediments. Structural changes of benthic communities and species diversity reduction occur under the influence of pollution.

One of the main features of zoobenthos and its individual representatives is the density (the ratio of the organisms number to the square unit), which is expressed by the abundance (ind. $\left./ \mathrm{m}^{2}\right)$ and biomass $\left(\mathrm{g} / \mathrm{m}^{2}\right)$.

Regulation of the Yenisei led to global changes in the zoobenthos of the river, first of all - to the spread of Baikal origin amphipods (crustaceans) above the Angara estuary. At the same time, their share in the Yenisei zoobenthos biomass increased by 10 times and they occupied a dominant position [3, 4]. It is known that crustaceans are among the most active aquatic organisms self-dispersing outside the natural habitat. In addition, in order to enrich the food supply for fish, the Baikal amphipods were successfully settled in many ponds and lakes of the USSR [5]. Invasions of these organisms lead to significant changes in the recipient water bodies, in particular, to a decrease in species diversity and stability of aquatic ecosystems [6].

The problem of environmental consequences assessment for the introduction of alien organisms in aquatic ecosystems is extremely important. The related issue of risk assessment for the aquatic organisms invasions is equally important. Consequences of the amphipods introduction, which belong to polluting species, are poorly studied and require long-term researches $[7,8]$.

\section{Geoinformation web-system}

It is believed that the first cartographic web application is the Map Viewer program created in 1993 by the Palo Alto Research Center (PARC) of the Xerox company, which allowed 
the users to interactively send requests from the browser to the server and receive fragments of maps in GIF format. This application and its functional concept became the ancestor for the majority of web mapping systems later versions. Roughly, since 1998 large companies manufacturers of GIS software entered the process of these systems creation: ESRI, Intergraph and others began to develop commercial applications for web mapping. Since the same moment of time, the most successful non-commercial open-source project MapServer started its history, the development of which began at the University of Minnesota. In subsequent years and nowadays, there is an intensive formation of the webcartography market. Numerous software developments appear - from simple visualization tools of prepared maps in the browser to complex distributed systems of corporate geoinformation processing [9-11].

The resulting concept of mapping web-application development involves the creation of a program complex, the execution of which is carried out simultaneously on the server computer and the client computer (multi-tier architecture), as well as formation of a spatial data set in the format of popular GIS or using geospatial databases [12]. The initial geodata preparation for web applications was carried out outside the web-GIS using the desktop GIS - QGIS [13].

The generated geospatial database content included the results of research expeditions data on the zoobenthos numbers and biomass in the Yenisei (from the Krasnoyarsk hydroelectric power station dam to the Angara river estuary), its distribution by species, banks of the Yenisei, depth, soil type, presence of higher aquatic vegetation.

Distinctive characteristics of the geoinformation web-system considered in this paper for the hydrobiological monitoring tasks solution are the following features [14]:

- integration of mapping web-application to the web content management system, its user access controls, administration and interface configuration, formation of the web portal information blocks;

- user interface improvement: creation of map and geodata controls in the style of traditional desktop GIS - floating panels with button instruments, interactive treelike dropdown menus with the map layer lists, contextual setting of data display properties, etc.;

- enhanced support for the geospatial data exchange between the mapping webapplication elements and other systems based on open technology standards - web services;

- used geospatial data kits design as directories with the appropriate metadata, creation of independent software for navigation and search for geoinformation in these directories. In the literature a lot of suchlike integrated geospatial data processing systems can be found, for example $[15,16]$.

User interface of the considered systems is made as a web resource with two access modes - user and administrative ones. The user interface is made for navigation and search for published information resources. The administrative interface allows editing of various data to create new information resources and manage their publication [17].

The development is based on PostgreSQL 8.x database with PostGIS module to store the spatial data, PHP 5.x script language to implement the application business logic. Formation of user and program interfaces was carried out with the help of many opensource libraries and technologies - Ext2js, TinyMCE, HTML_MetaForm, Smarty, PEAR, Zend Framework and others.

\section{Hydrobiological studies results}

The materials are a part of the complex work "Determination of forage resources production potential for the Yenisei river fish at the section from the Krasnoyarsk hydroelectric power station dam to the village Zotino", which was started back in the 2000 s. The primary role in the fish forage resources of the considered area belongs to the 
benthic fauna. One of the main objectives was to evaluate changes in the river benthic fauna after the regulation.

According to physical and geographical conditions, the structure of the river valley and bed, the water regime, the Yenisei is divided into the upper (source - the Angara estuary), middle (the Angara - the Lower Tunguska estuary) and lower (the Lower Tunguska - the Yenisei estuary) areas. The studies covered a section of about $780 \mathrm{~km}$ long in the middle of the Yenisei River: $325 \mathrm{~km}$ - in the mountainous Upper Yenisei (from the Krasnoyarsk hydroelectric power station dam to the Angara estuary) and $456 \mathrm{~km}$ - in the semimountainous Middle Yenisei (from the Angara estuary to the village Zotino). During carrying out the field work for the selection of zoobenthos samples, 10 sections were selected in the specified part of the Yenisei.

Screening and treatment of the benthic samples were carried out according to standard hydrobiological methods [18]. In each section, the soil sampling was carried out at both banks at two depth (D) gradations (less than $1 \mathrm{~m}$ and 1 to $2 \mathrm{~m}$ ) using a circular Dulkeit's scraper (capture area $1 / 9 \mathrm{~m}^{2}$ ) designed specially for the Yenisei in the 1930s. During the hydrobiological material collecting, watercourse depth, water temperature, flow rate, soil type and degree of the watercourse overgrowing with macrophytes (aquatic vegetation) were determined.

During the period of studying, about 300 samples of zoobenthos were collected and processed in the Yenisei and its tributaries. All results were statistically processed using Microsoft Excel and Statistica 9 software. In Figure 1, aggregate data is presented in the form of arithmetic averages, average errors, confidence intervals. Student's t-criterion was used for the data comparison with a probability of $95 \%(p=0.05)$.
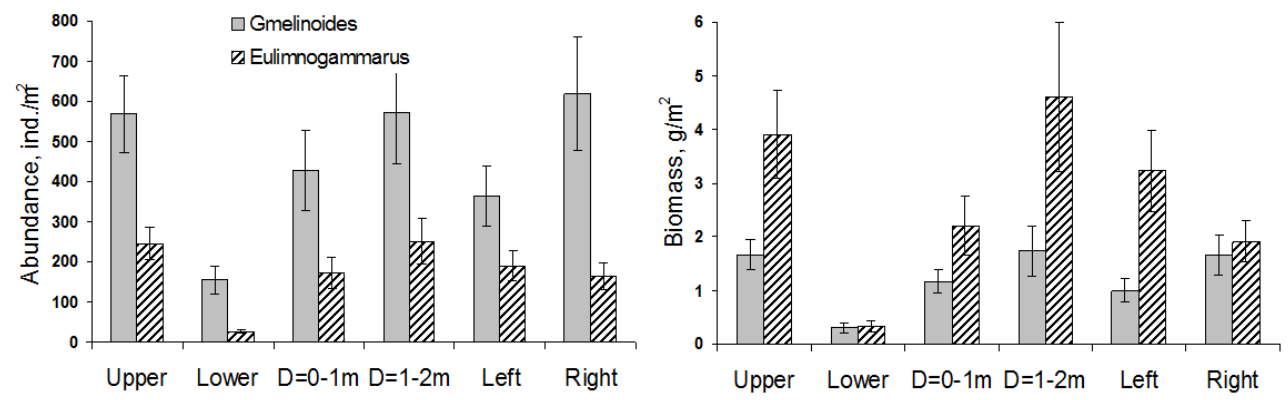

Figure 1. Spatial distribution of the Baikal amphipods in the Yenisei.

To form the geospatial database, materials on the spatial distribution of amphipods were used, which currently dominate among the Yenisei zoobenthos communities. In the studied area, seven species of amphipods were identified, but only two species, which are endemic to Baikal, massively develop and clearly dominate among them: Eulimnogammarus viridis Dybowsky, 1874 and Gmelinoides fasciatus Stebbing, 1899.

The spatial dynamics of the amphipods quantity and biomass in the Yenisei (Figure 1) is characterized by inhomogeneous distribution, but a clear decline trend is obvious in the transition from the upper to the lower section (i.e., above and below the Angara).

It was revealed that the number of Gmelinoides exceeds the number of Eulimnogammarus more than twice in the upper section and more than five times in the lower section. It is known that the Gmelinoides amphipod is very ecologically plastic. He is hardy to significant eutrophication, resistant to a number of pollutants, can adapt to a range of adverse factors and thus is one of the first species to colonize habitats contaminated with industrial waste [19]. 
It is believed that the right bank of the Yenisei is more productive due to its more extensive river network. Gmelinoides abundance and biomass are really slightly higher at the right bank; for Eulimnogammarus, this trend is not noted. In addition, a slight tendency to increase the quantity and biomass of both amphipods species with depth is revealed.

\section{Data presentation with GIS}

The first step in the web-GIS creation for hydrobiological monitoring was the formation of a geospatial data set for the field research results registration in the GIS and visualization of the results [20]. In particular, the work on the sailing sheets georeference to satellite images was carried out by locally-affine transformations (at least 15 points for each sheet), layers of vector data with the fairway, kilometer markers, watercourse alignment, etc. were created. To visualize various data on the fairway and river banks (left/right), a series of specialized polygonal and linear layers was also formed.

In the second step, conversion algorithms were developed for the calculation and generalization of the initial hydrobiological monitoring data array into the geopositioning values system taking into account the used data aggregation. As a result of the software performance, thematic geodata layers are formed, visualization of which is made by regular means of the ICM SB RAS geoportal.

The considered geoinformation web-system is built according to so-called serviceoriented architecture - it can be regarded as a set of interrelated software components for spatial data operations - its import/export, cataloging, visualizing, creating, processing, distribution, etc $[21,22]$. The technological basis is a set of program interface libraries; they provide access to the functions and context of web pages mapping elements, thematic data visualization. The main characteristics of the system are high degree of the user interface interactivity, very fast regeneration of images made of small caching raster fragments (tiles), almost instant response of the move (shift) and map scale change tools, extensive settings of visualization and geodata management. Support of geodata exchange standards KML, GML, WMS, etc. is provided [23].

From the organizational point of view, the created system is based on the ICM SB RAS geoportal. The geoportal is a type of web portal used to access and search for geographic (geospatial) information and related geographic web services (access, editing, and so on). It is one of the spatial data infrastructure key components. The geoportal functionality is closely associated with metadata management subsystem, means of spatial analysis, interactive visualization [24]. A popular CMS system - Drupal web content management system - was selected as a basis for the content publication.

\section{Conclusions}

It should be noted that the experience of various research and applied systems design and development shows high efficiency of using geoinformation web-systems and services as the foundation for information and analytical resources and geospatial data integration.

Modular architecture of the system, the use of standard web services to exchange data between these modules provide rapid adaptation of existing software to customer's requirements, replication of individual components, their complementarity. In turn, registration of created resources - spatial data in the centralized geoportal directory provides the ability to re-use them. This service-oriented approach based on active introduction of web technologies in the applied information systems is increasingly used today. 


\section{Acknowledgments}

The work was supported by grant no. 16-47-240517 from Russian Foundation for Basic Research and Krasnoyarsk Regional Fund of Support of Scientific and Scientific-technical activities.

\section{References}

[1] L. Berrahou, N. Lalande, E. Serrano, G. Molla, L. Berti-Équille, S. Bimonte, S. Bringay, F. Cernesson, C. Grac, D. Ienco, F. Le Ber, M. Teisseire, Computers \& Geosciences 85, 126 (2015) doi: 10.1016/j.cageo.2015.09.012

[2] Li Li, B. Zheng, L. Liu, Procedia Environmental Sciences 2, 1510 (2010) doi: 10.1016/j.proenv.2010.10.164

[3] A.V. Andrianova, Tomsk State University Journal of Biology 1, 74 (2013)

[4] M.I. Gladyshev, A.V. Moskvicheva, Doklady Biological Sciences 383, 138 (2002)

[5] D.V. Matafonov, R.M. Kamaltynov, M.T. Itigilova, Sibirskiy ekologicheskiy zhurnal 5, 595 (2006)

[6] N.A. Berezina, Hydrobiologia 590 (1), 15 (2007) doi: 10.1007/s10750-007-0753-z

[7] R. Liu, T. Xie, Q. Wang, H. Li, Procedia Environmental Sciences 2, 1307 (2010) doi: 10.1016/j.proenv.2010.10.141

[8] J. Graham, G. Newman, C. Jarnevich, R. Shory, T. J. Stohlgren, Ecological Informatics 2, 177 (2007) doi: 10.1016/j.ecoinf.2007.03.006

[9] O.E. Yakubailik, V.G. Popov, Computational Technologies 6, 116 (2009)

[10] A. Vyas, S. John, MATEC Web of Conferences 57, 05002 (2016) doi: $10.1051 /$ matecconf $/ 20165705002$

[11] X. Jin, D. Guo, S. Wang, X. Zhao, Y. Song, A. Liu, MATEC Web of Conferences 22, .04027 (2015) doi: 10.1051/matecconf/20152204027

[12] M.K. Yetik, M. Yüceer, R. Berber, E. Karadurmuş, IFAC Proceedings Volumes (IFAC-PapersOnline) 7,798 (2009)

[13] A.A. Kadochnikov, V.G. Popov, A.A. Tokarev, O.E. Yakubailik, Journal of Siberian Federal University Engineering \& Technologies 4, 377 (2008)

[14] P. Yue, M. Zhang, Z. Tan, Environmental Modelling \& Software 69, 128 (2015) doi: 10.1016/j.envsoft.2015.03.017

[15] X.-1. Xie, Z. Long, W.-Q. Liao, X.-J. Guo, MATEC Web of Conferences 56, 01013 (2016) doi: 10.1051/matecconf $/ 20165601013$

[16] C. P. Korose, R.A. Locke, C. S. Blakley, C. H. Carman, Energy Procedia 63, 3945 (2014) doi: 10.1016/j.egypro.2014.11.424

[17] O.E. Yakubailik, Vestnik of SibGAU 1, 40 (2010)

[18] E. Comino, M. Bottero, S. Pomarico, M. Rosso, Land use policy 36, 381 (2014) doi: 10.1016/j.landusepol.2013.09.006

[19] M.A. Barbashova, S.A. Malavin, E.A. Kurashov, Russian Journal of Biological Invasions 4, 219 (2013) doi : 10.1134/S2075111713040036

[20] Q.-G. Liu, Y. Chen, J.-L. Li, L.-Q. Chen, Ecological Modelling 203, 279 (2007) doi: 10.1016/j.ecolmodel.2006.11.028

[21] Z. Qun, Y. Yujin, K. Yuena, Physics Procedia 25, 2235 (2012) doi: $10.1016 /$ j.phpro.2012.03.376

[22] S. Borza, V. Petrescu, Process Safety and Environmental Protection 101, 9 (2016) doi: 10.1016/j.psep.2016.01.002

[23] O.E. Yakubailik, A.A.Gosteva, M.G. Erunova, A.A. Kadochnikov, A.G. Matveev, A.S. Pyataev, A.V. Tokarev, Vestnik of KemSU 52, 136 (2012) 
[24] Nina M Kelly, Karin Tuxen, Computers, Environment and Urban Systems 27, 527 (2003) 